\title{
Crowd Gathering and Thermal Comfort Research in Different Park Shading Spaces
}

\author{
Qindong Fan, Xiaofeng $\mathrm{Li}$ and $\mathrm{Hu} \mathrm{Li}$ *
}

check for

updates

Citation: Fan, Q.; Li, X.; Li, H. Crowd Gathering and Thermal Comfort Research in Different Park Shading Spaces. Sustainability 2022, 14, 2687. https://doi.org/10.3390/su14052687 Academic Editor: Vincenzo Costanzo

Received: 22 January 2022 Accepted: 21 February 2022 Published: 25 February 2022

Publisher's Note: MDPI stays neutral with regard to jurisdictional claims in published maps and institutional affiliations.

Copyright: () 2022 by the authors Licensee MDPI, Basel, Switzerland. This article is an open access article distributed under the terms and conditions of the Creative Commons Attribution (CC BY) license (https:// creativecommons.org/licenses/by/ $4.0 /)$.
College of Archictecture, North China University of Water Resources and Electric Power, Zhengzhou 450000, China; qindongf@ncwu.edu.cn (Q.F.); z20201140973@stu.ncwu.edu.cn (X.L.)

* Correspondence: z20201140965@stu.ncwu.edu.cn

\begin{abstract}
The thermal comfort of different shaded spaces in parks varies noticeably, and it is also a key factor influencing crowd gathering. Longzi Lake Beach Park in Zhengzhou was used as a study area in this research. For analysis, a thermal comfort index for three different space types (unshaded, semi-shaded, and fully-shaded) and a crowd aggregation index were used. The results show that during autumn, visitors are sensitive to the thermal comfort in different shaded spaces, and that the location of the playing field differs significantly. Air temperature and solar radiation are the two factors that influence tourists' thermal comfort the most. For the first time, a regression relationship between physiological equivalent temperature (PET) and mean thermal sensation vote (MTSV) is established in different shading spaces. It clarified the thermal comfort of tourists in different shaded spaces. PET and crowd aggregation index show a clear correlation. The correlation between the MTSV and crowd aggregation density increased with the increase in shade area. For the first time, the relationship between thermal comfort and crowd gathering in different shaded spaces in parks was analysed. The research is beneficial to improving the scientificity of the construction of the park's thermal environment, and providing people with more comfortable outdoor space from the perspective of shading.
\end{abstract}

Keywords: park; different shading space; thermal comfort; crowd gathering

\section{Introduction}

Urban thermal environment problems have a great impact on human health [1]. Parks are important parts of urban green infrastructure, which can effectively alleviate the urban heat island effect and provide residents with a comfortable thermal environment [2]. At present, the construction of parks is mostly from the perspective of aesthetics and ecology, lacking the consideration of thermal comfort. In particular, there exists a serious lack of research on the relationship between crowd gathering and different shading spaces from the perspective of thermal comfort. Strengthening the research on the distribution of people flow under the background of different shade spaces in the park has a positive impact on improving the construction level of the park and meeting people's thermal comfort needs [3].

Thermal comfort is defined as a subjective satisfaction evaluation of the surrounding thermal environment. It has a significant impact on people's environmental experience and site interaction [4,5]. Thermal comfort research mainly includes physical, physiological, and psychological aspects. The physical aspect includes air temperature, relative humidity, shadow rate, and wind speed [6]; the physiological aspect includes skin temperature, skin humidity, perspiration rate, blood pressure, and body temperature [7]; and the psychological aspect includes people's subjective feelings in a hot environment, sex, age, and emotion [8-10]. Questionnaire investigation and field measurement are the basic research methods of thermal comfort evaluation, and simulation analysis is the major means of mapping and predicting thermal comfort evaluation results [11]. ENVI-met is a software 
platform that uses thermodynamics, fluid simulation, and plant physiology to comprehensively consider the effects of spatial layout, surface material, waterbody, vegetation cover, and other factors on different spatial microclimate environments, and carry out dynamic evaluation and simulation in thermal comfort simulation [12,13].

Currently, cities house more than half of the world's population [14]. The thermal comfort of urban residents has a significant impact on their living experience. Since urban interior space is relatively easy to control owing to its closeness, the evaluation, simulation, and optimization of outdoor space thermal comfort have gradually become the focus of academic research $[15,16]$. In the research of outdoor space thermal comfort, predicted mean vote (PMV), outdoor standard effective temperature (OUT_SET*), physiological equivalent temperature (PET), and universal thermal climate index (UTCI) are the mainstream evaluation indices [17]. According to a study on outdoor thermal comfort suitable for steady-state, PMV is the most representative thermal comfort evaluation index as it reflects the subjective thermal sensation of most people in the same environment [18]. However, because people differ in their feelings, PMV indicators do not necessarily represent the feeling of every individual. Therefore, the prediction of different hot and cold environments by PMV is not accurate. According to research, the difference in cold environments is greater than that in hot environments [19]. OUT_SET* reflects the average skin temperature in a standard environment and the air temperature when the skin wettability is the same as that in the actual environment [20]. OUT_SET, in contrast to PMV, considers the human body's skin temperature and moisture, according to a study on thermal comfort prediction commonly used in steady-state [21]. PET is a biometric parameter that describes an individual's thermal perception [22], and it is widely used in the prediction of thermal comfort in steady-state environments, thermal environment assessment with large seasonal temperature differences, and urban thermal environment planning and design [23]. UTCI focuses on the analysis of physiological and thermal responses that reflect all parts of the human body, and can adapt to the characteristics of different climates, seasons, and latitudes, making it suitable for dynamic human thermal comfort research.

In outdoor space, light is the main source of thermal radiation [24]. However, owing to the complexity of outdoor space, the shading of different buildings and plants to sunlight creates a large number of shadow spaces. The study of the differences between different shaded spaces has become an unavoidable problem in the evaluation of outdoor thermal comfort. In recent years, research on the thermal comfort evaluation of different outdoor shaded spaces based on the sky view factor (SVF) has been gradually increasing [25]. According to research, human thermal comfort is significantly negatively correlated with the SVF in different shaded spaces on the same site; there is a significant difference between unshaded, semi-shaded, and fully-shaded spaces, but there is little difference in thermal environment between fully-shaded and semi-shaded spaces [26]. Some scholars have also conducted cross-season studies of the same shaded space-for example, in the shadow of the same plant in different seasons in winter and summer-and found that the thermal comfort sensitivity of the human body differs significantly [27]. According to research, the thermal comfort of different outdoor shading spaces varies significantly. Therefore, changing the shading degree of outdoor space can improve outdoor space thermal comfort [28].

Parks are important living spaces for urban residents since they are an integral component of the urban ecosystem and urban landscape [29]. There are many different types of shaded spaces in parks, owing to the complexities of park landscapes. The thermal comfort of different shading spaces significantly influences the distribution of people in the park and the use efficiency of the park [30]. In recent years, RS (remote sense), GIS (geo-information system), and GPS (global position system) technology, mobile phone signalling data, and the application of the Baidu Heat Map have all become popular, as they provide a new perspective for the analysis of people flow in different park spaces. Among them, the Baidu Heat Map takes the positioning information used by people on Baidu software as its spatial data source, which has become a new way to study the distribution of 
people in China [31,32]. When combined with the related literature, research on people clustering based on mobile phone signalling data and the Baidu Heat Map currently includes cities, tourist attractions [33], historic districts [34], traffic stations [35], and other locations. The majority of studies, such as crowd aggregation in different shading spaces, focus on the macro-scale aspects, without considering micro-scale aspects. Furthermore, in-depth research on the relationship between PET and mean thermal sensation vote (MTSV) in different shaded spaces has not yet been conducted. This study employed the Baidu Heat Map as a tool to explore the relationship between the thermal comfort of different shaded spaces in small-scale parks and the degree of crowd gathering. The present study proposes a thermal comfort construction strategy for different shaded spaces in the park based on the quantitative results, in order to provide a reference for the humanised design of thermal comfort in parks, thereby improving the scientificity of the park's thermal environment construction, and providing the theoretical basis and a case reference for the humanized design of the park's thermal comfort

\section{Materials and Methods}

\subsection{Research Hypothesis and Research Path}

According to previous studies, the degree of thermal comfort is different in different shading spaces. Given that people choose different stay spaces according to thermal comfort, what impact will shading space have on crowd aggregation? This is our research hypothesis (Figure 1a), and our research path is as follows (Figure 1b)

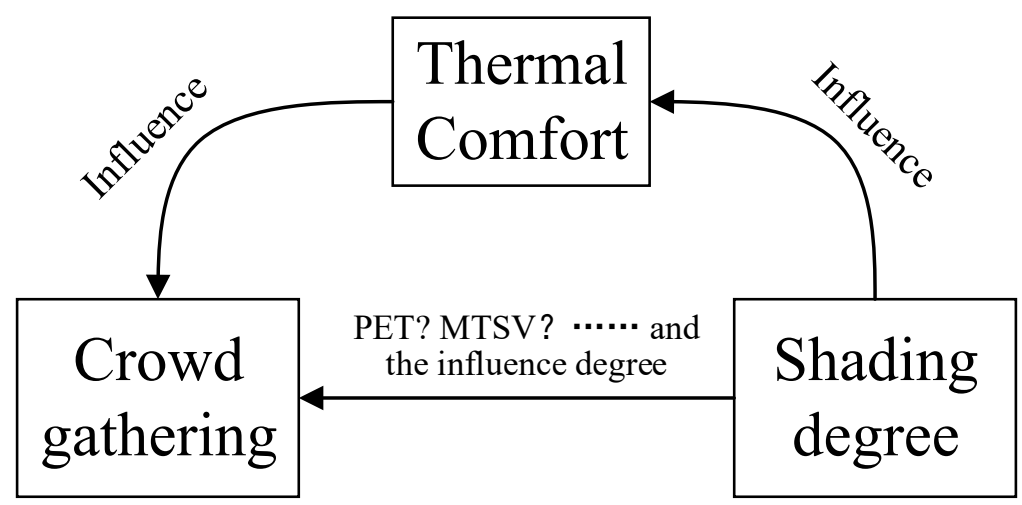

(a)

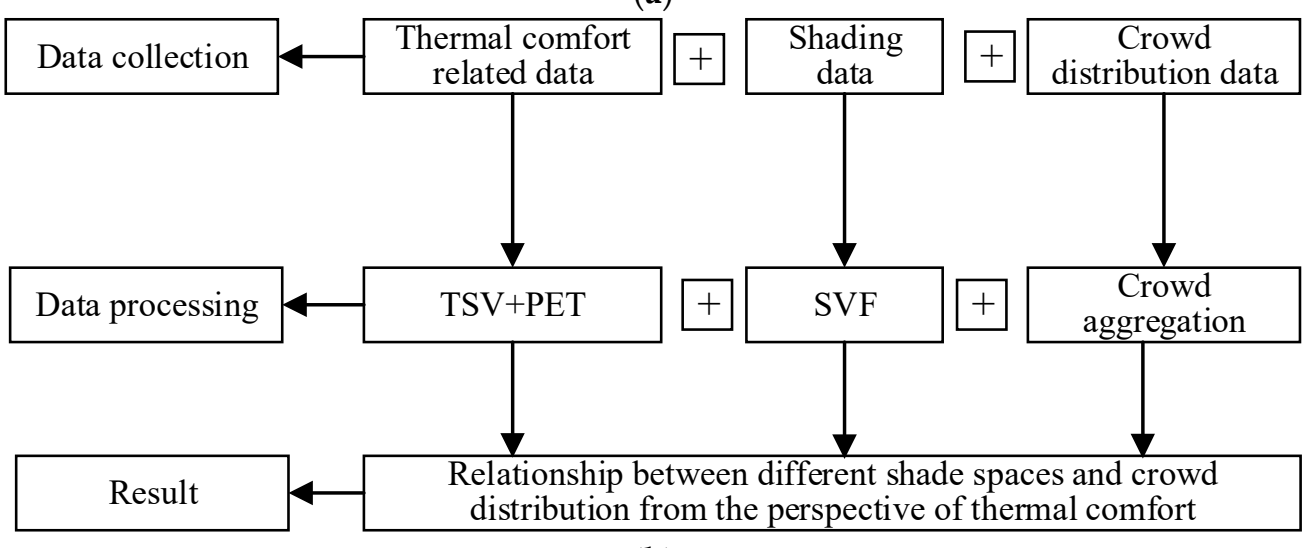

(b)

Figure 1. (a) Research fame. (b) Research path.

\subsection{Research Site}

Longzi Lake Beach Park was selected as the research site. It has a temperate continental climate, with four distinct seasons, an average annual temperature of about $22{ }^{\circ} \mathrm{C}$, and 
relative humidity of about $55 \%$. The annual temperature and humidity fluctuations are shown in Figure 2 below.

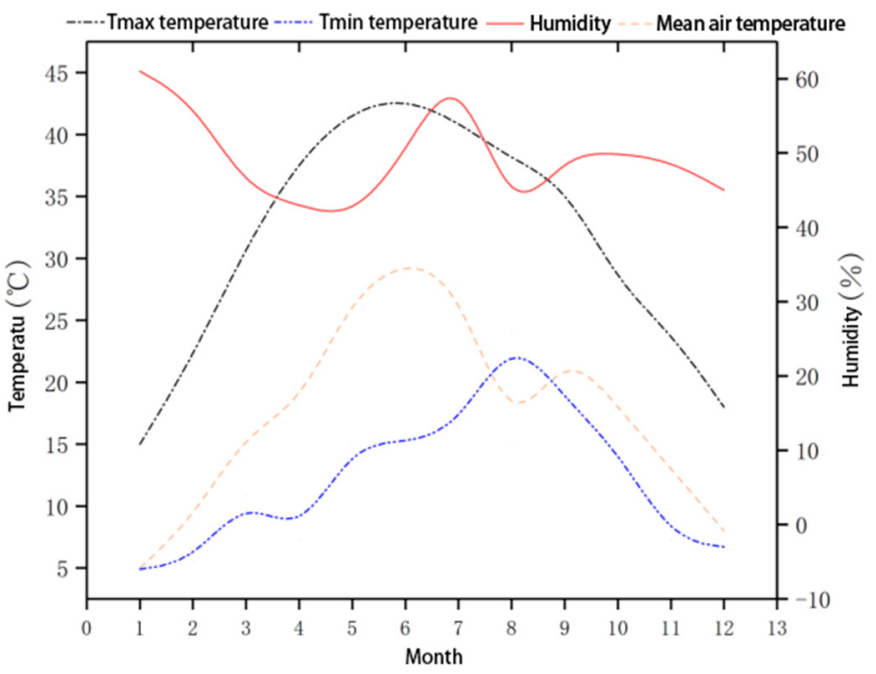

Figure 2. Map of the study area.

The venue is located in the southwest of Longzi Lake College, Jinshui District, Zhengzhou City, Henan Province, China, at longitude $112^{\circ} 42^{\prime} \sim 114^{\circ} 14^{\prime}$ east, between $34^{\circ} 16^{\prime}$ and $34^{\circ} 58^{\prime}$ north latitude. The total area is about 11.25 hectares. The beach park is an important part of the green space around the lake, as well as a popular hangout spot for locals and college students. It also has a relatively stable flow of people. In this study, ten different shading spaces were selected as measuring points. The specific location distribution of the measuring points is shown in Figure 3.

SVF quantifies the shading degree of each measuring point by comparing the visible portion pixel value of the top shade cover captured by the fisheye lens with the overall spatial pixel value. The calculation method is shown in Formula (1), and the ranges of SVF value for the shading condition (no, half, and full) is in Table 1.

$$
\varepsilon=1-a A
$$

In Formula (1), $\varepsilon$ is the density of canopy, $A$ is the canopy pixel value, and $a$ is the pixel value of the gap in the forest canopy.

Table 1. Different shade space range.

\begin{tabular}{cccc}
\hline & No-Shade & Half-Shade & Full-Shade \\
\hline SVF & SVF $\geq 0.95$ & SVF $\approx 0.5$ & SVF $\leq 0.25$ \\
\hline
\end{tabular}

On the basis of field measurement, according to Formula (1) and Table 1, we get the SVF value of each measuring point and divide it into three categories: full-shading, no-shading, and half-shading (Figure 4). 


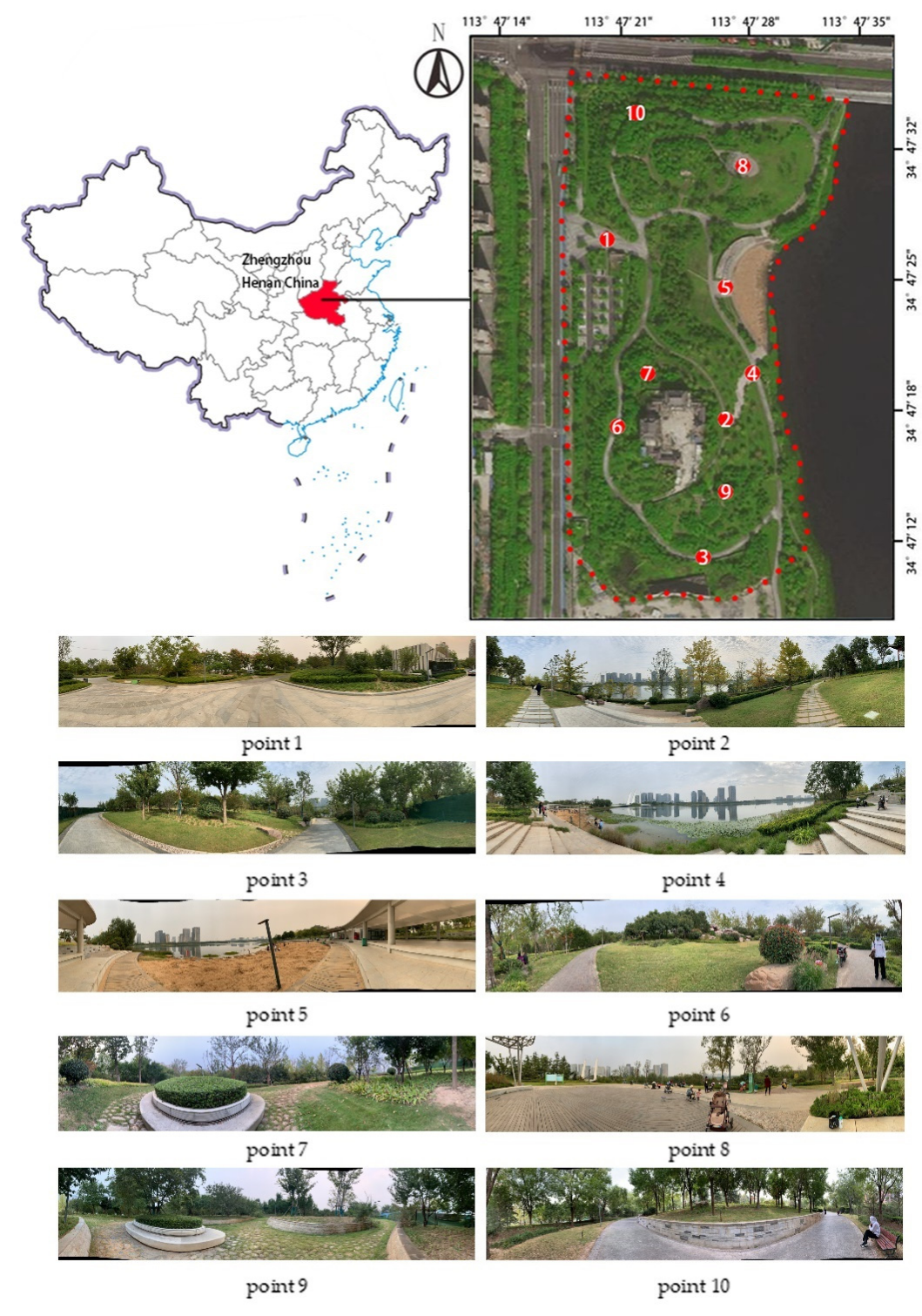

Figure 3. Distribution and current situation of measuring points.

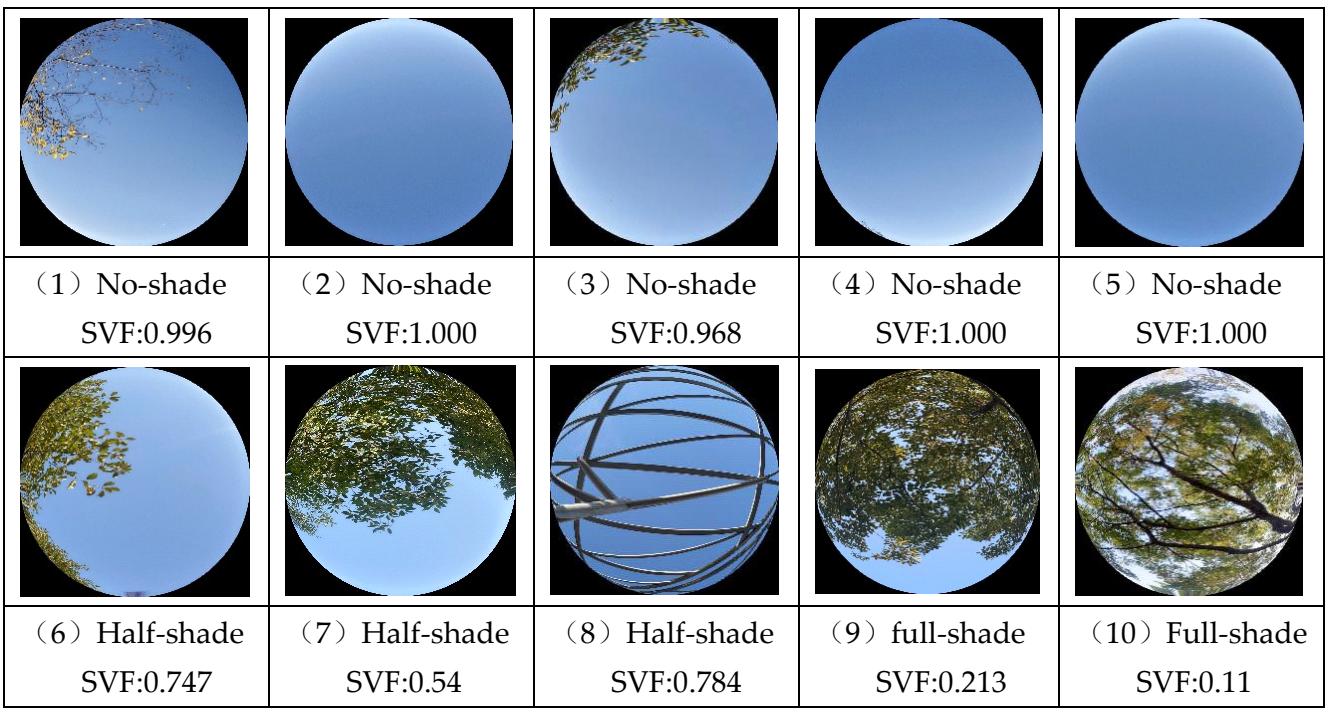

Figure 4. SVF of the study area. 


\subsection{Data Sources}

The site is located in the southwest of the Longzihu University District, Jinshui District, Zhengzhou City, Henan Province, China, between longitude $112^{\circ} 42^{\prime}$ and $114^{\circ} 14^{\prime}$, latitude $34^{\circ} 16^{\prime}$ and $34^{\circ} 58^{\prime}$, with a total area of about 11.25 hectares. As an important part of the green space around the lake, the beach park is selected as the study area for the following reasons: (1) the site is located inside the city and the microclimate is relatively stable; (2) there are many types of shade spaces in the park which are easy to reach; and (3) there are large flows of people and fixed visitors in the park. Ten different shading spaces were selected as the measuring points. The specific location distribution of the measuring points is shown in Figure 5.
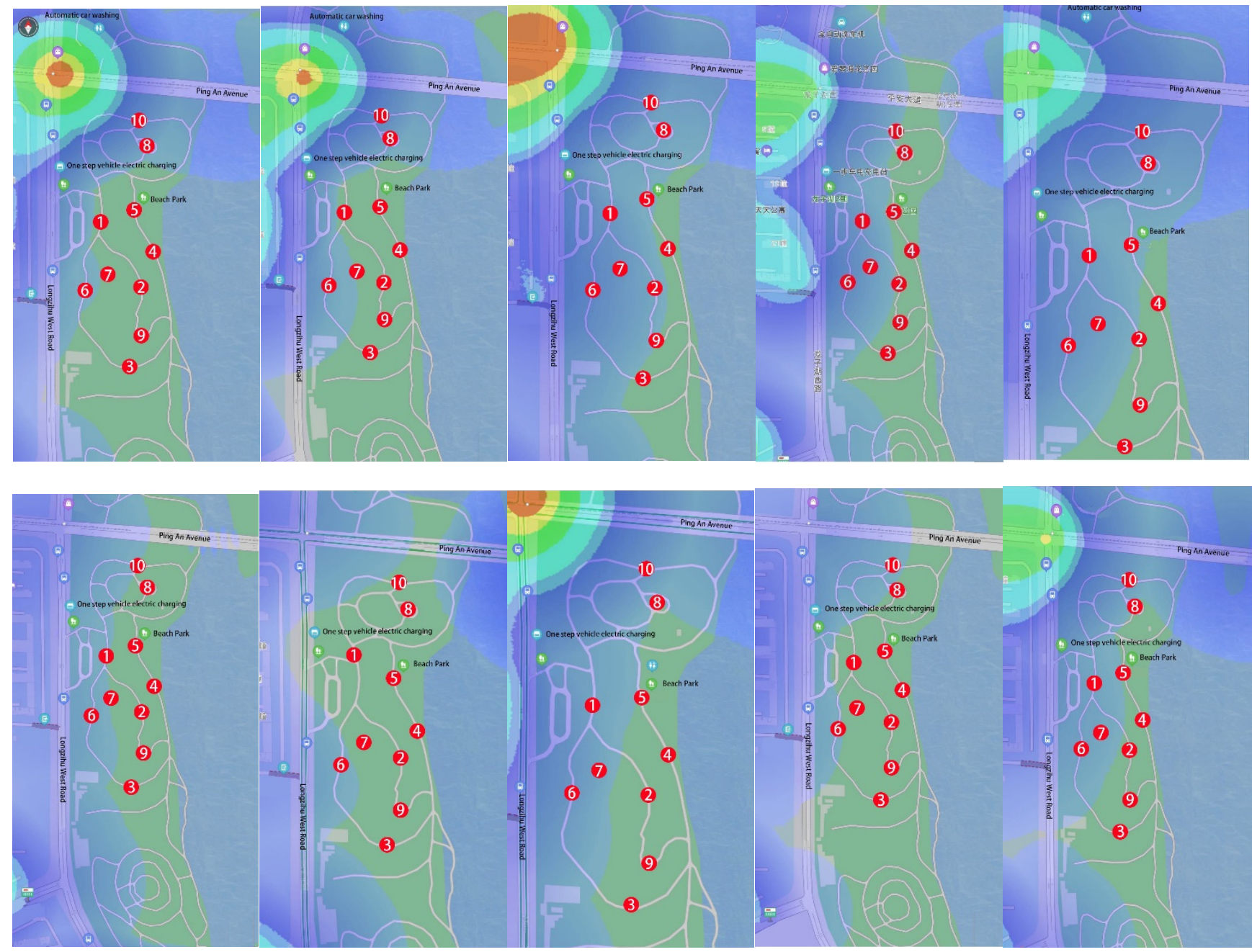

Figure 5. Partial thermal diagram of Longzi Lake Beach Park in Zhengzhou from 9:00 to 19:00 in a week.

\subsection{Research Methods}

(1) Analysis of crowd agglomeration density

The crowd gathering degree in the park was quantified using the crowd heat in$\operatorname{dex}[36,37]$. The calculation formula is as follows:

$$
\mathrm{P}=\mathrm{H}_{\mathrm{t}} / \mathrm{S} \times \mathrm{k}
$$

In the formula, $\mathrm{P}$ is the population heat index, $\mathrm{H}_{\mathrm{t}}$ is the calculated mean value of heat in different periods, $\mathrm{S}$ is the pixel area of the sample area, and $\mathrm{k}$ is the calculation coefficient. 
(2) PET

PET can accurately evaluate the heat budget of the human body when the core and skin temperatures are the same as the air temperature under the complex outdoor conditions to be evaluated [38]. Microclimate observation instruments (air temperature, relative humidity, wind speed, and blackball temperature) measure the values of meteorological parameters at different periods and different measuring points. The aforementioned data were entered into the Rayman model to obtain the corresponding human body PET value. Table 2 shows the standard PET parameters.

Table 2. PET $\left({ }^{\circ} \mathrm{C}\right)$ parameters.

\begin{tabular}{cccccccccc}
\hline Index & Chill & Cold & Cool & Slightly Cooler & Comfortable & Slightly Warmer & Warm & Hot & Extremely Hot \\
\hline PET $\left({ }^{\circ} \mathrm{C}\right)$ & $<4$ & $4 \sim 8$ & $8 \sim 13$ & $13 \sim 18$ & $18 \sim 23$ & $23 \sim 29$ & $29 \sim 35$ & $35 \sim 41$ & $>41$ \\
\hline
\end{tabular}

(3) TSV (thermal sensation vote) and MTSV

TSV is based on the human body's primary description of whether the surrounding environment is 'cold' or 'hot', and the ASHRAE 5 scale is usually used as the evaluation standard (see Table 3). TSV data were obtained using a questionnaire survey of 10 measuring points on the site, where MTSV is the mean value of the TSV.

$$
\mathrm{MTSV}=\frac{\sum_{n}^{j} \mathrm{TSV}}{n}
$$

In the formula, $n$ is the TSV number in each thermal index.

Table 3. TSV Standards.

\begin{tabular}{cccccc}
\hline Index & Cool & Slightly Cooler & Moderate & Slightly Warmer & Warm \\
\hline TSV & -2 & -1 & 0 & 1 & 2 \\
\hline
\end{tabular}

(4) Thermal neutral temperature and range

The thermal neutral temperature threshold is defined as the temperature at which people feel neither hot nor cold in their environment, a state of feeling 'moderate', that is, the PET temperature at MTSV $=0$. The range of thermal neutral temperature can also be obtained using TSV voting criteria. The thermal neutral temperature range reflects the temperature variation range of different thermal sensations.

(5) Analysis of correlation between thermal comfort index and crowd aggregation in different shading spaces.

The strength of the three linear correlations was analysed using Pearson correlation from PET, MTSV, and crowd aggregation degree data in three shading space types.

\section{Research Results}

\subsection{Crowd Aggregation Analysis}

Based on the statistical calculation of the thermal maps of ten measuring points in the park over 1 week, a heat map measuring point frequency was drawn (Figure 6). The frequency of the measuring point 10 in the full-shade was the highest in a week, as shown in Figure 6. The temperature and humidity at the semi-shaded point 8 were relatively moderate throughout the day, with no major ups and downs. The unshaded site 1 is the main entrance of the park, and the heat map frequency is relatively high. 


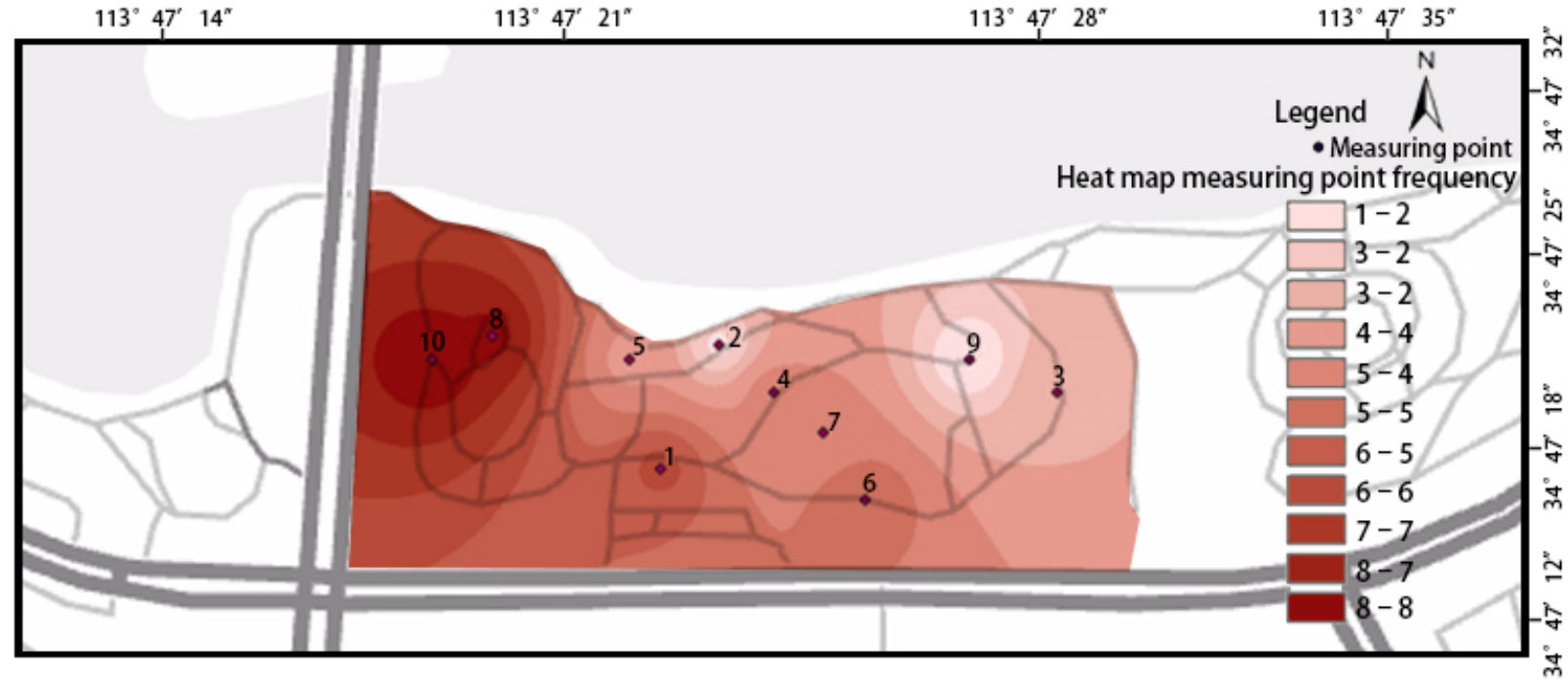

Figure 6. Heat map measuring point frequency diagram.

\subsection{Park TSV and PET Analyses}

Figure 7 shows the distribution of TSV in three different types of shaded spaces based on TSV data collected from the different spaces. The highest proportion of unshaded votes was 'warm', with overall voting primarily 'warm' and 'slightly warmer'; the highest proportion of votes in the half-shaded space was 'moderate', followed by 'warm' and 'slightly cool'; the highest proportion of votes in the full-shaded space was 'moderate', with the voting focused on 'moderate' to 'cool'. TSV varied significantly between unshaded, falf-shaded and full-shaded spaces, indicating a 'warm-moderate-cool' transition.

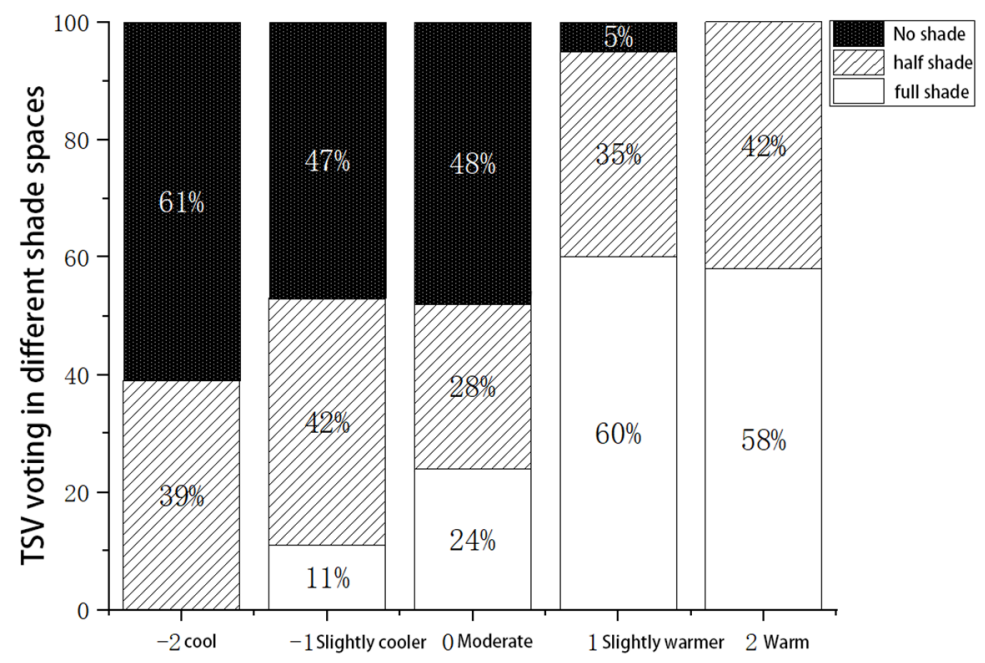

Figure 7. TSV distribution.

The overall PET value of the full-shaded space was lower than that of the other two space types, which were mostly moderate and cool, as shown in Figure 8. The PET values of the semi-shaded and unshaded spaces were roughly the same, mostly warm. However, in comparison to the unshaded space, the half-shaded space began to appear 'cool', and the time when the PET value of the half-shaded space was 'cool' was the same as that of the full-shaded space. The results show that the PET value corresponding to the peak of the crowd gathering index of the three shaded spaces was lower than the standard PET value, indicating that tourists in the autumn park required a reduced temperature. 


\begin{tabular}{|c|c|c|c|c|c|c|c|c|c|c|c|}
\hline \multicolumn{12}{|c|}{ No shade space } \\
\hline $21.6^{\circ} \mathrm{C}$ & $19.5^{\circ} \mathrm{C}$ & $24.1^{\circ} \mathrm{C}$ & $25.3^{\circ} \mathrm{C}$ & $27.6^{\circ} \mathrm{C}$ & $28.6^{\circ} \mathrm{C}$ & $26.5^{\circ} \mathrm{C}$ & $26.3^{\circ} \mathrm{C}$ & $23.7^{\circ} \mathrm{C}$ & $21.7^{\circ} \mathrm{C}$ & $19.6^{\circ} \mathrm{C}$ & $\begin{array}{l}\text { Gotren } \\
\text { hot } \\
\text { Hot }\end{array}$ \\
\hline 9:00 & $10: 00$ & $11: 00$ & $12: 00$ & $13: 00$ & $14: 00$ & $15: 00$ & $16: 00$ & $17: 00$ & $18: 00$ & $19: 00$ & Warm \\
\hline \multicolumn{11}{|c|}{ half shade space } & $\begin{array}{l}\text { Slightly } \\
\text { warmer } \\
\text { Camfor }\end{array}$ \\
\hline $17.4^{\circ} \mathrm{C}$ & $19.9^{\circ} \mathrm{C}$ & $24.4^{\circ} \mathrm{C}$ & $24.3^{\circ} \mathrm{C}$ & $26.8^{\circ} \mathrm{C}$ & $25.2^{\circ} \mathrm{C}$ & $24.8^{\circ} \mathrm{C}$ & $25.2^{\circ} \mathrm{C}$ & $19.8^{\circ} \mathrm{C}$ & $18.7^{\circ} \mathrm{C}$ & $17.1^{\circ} \mathrm{C}$ & $\begin{array}{l}\text {-tablet } \\
\text { Slightly }\end{array}$ \\
\hline \multicolumn{11}{|c|}{ full shade space } & \multirow{3}{*}{$\begin{array}{l}\text { Cool } \\
\text { Cold } \\
\text { Chill }\end{array}$} \\
\hline $14.2^{\circ} \mathrm{C}$ & $16.2^{\circ} \mathrm{C}$ & $18.5^{\circ} \mathrm{C}$ & $19.0^{\circ} \mathrm{C}$ & $25.8^{\circ} \mathrm{C}$ & $22.1^{\circ} \mathrm{C}$ & $22.9^{\circ} \mathrm{C}$ & $24.9^{\circ} \mathrm{C}$ & $21.3^{\circ} \mathrm{C}$ & $16.8^{\circ} \mathrm{C}$ & $14.2^{\circ} \mathrm{C}$ & \\
\hline 9:00 & $10: 00$ & $11: 00$ & $12: 00$ & $13: 00$ & $14: 00$ & $15: 00$ & $16: 00$ & $17: 00$ & $18: 00$ & $19: 00$ & \\
\hline
\end{tabular}

Figure 8. Distribution of PET values of spatial types.

\subsection{TSV and PET Analyses in Different Shading Spaces of the Park}

Figures 9-11 show the results of combining TSV and PET data from 10 sites in the same area and fitting the relationship between TSV and PET using a scatter plot. The slope of the fitting curve for the unshaded space was significantly higher than that of the other two types of shaded space, indicating that visitors' perception of the thermal environment in the unshaded space was more sensitive than that in the half-shaded space and full-shaded space.

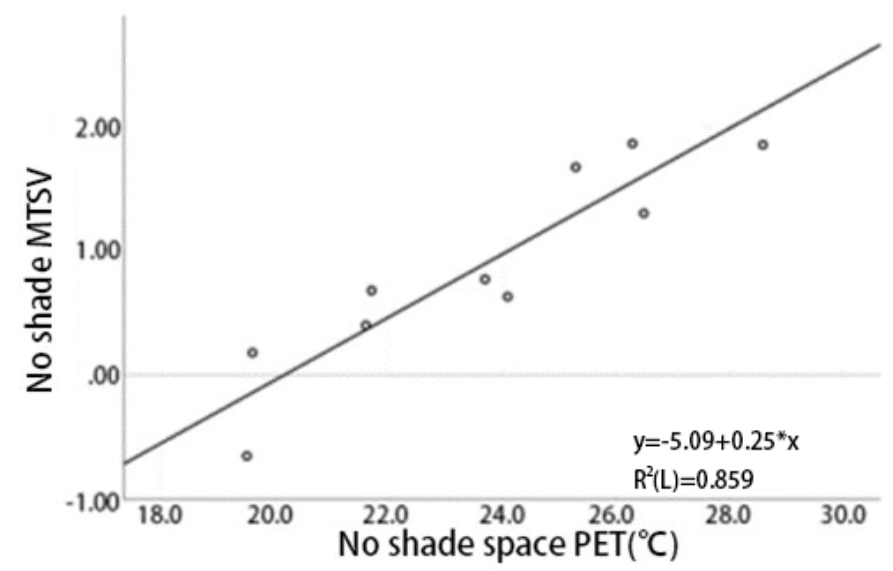

Figure 9. No-shade PET and MTSV regression map.

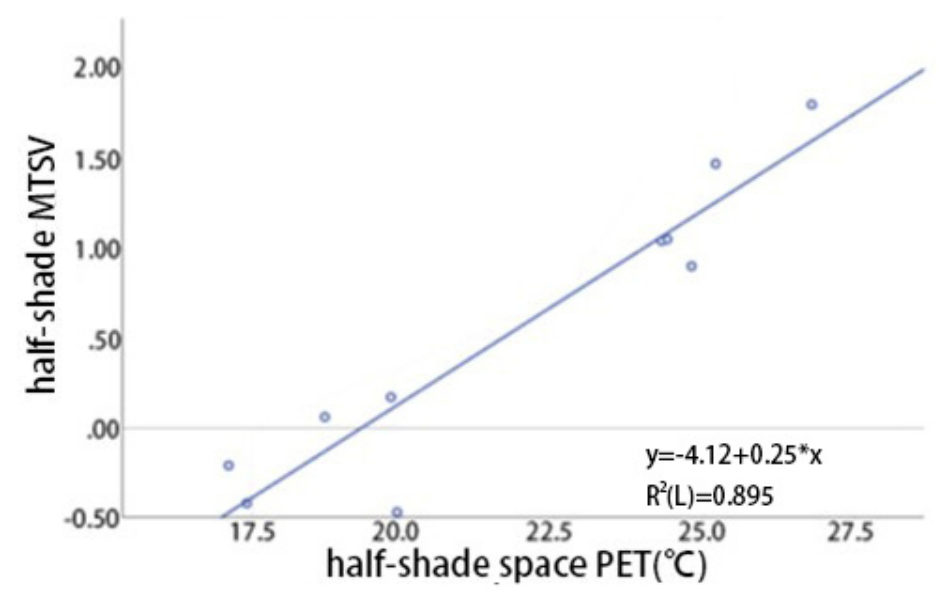

Figure 10. Half-shade PET and MTSV regression map. 


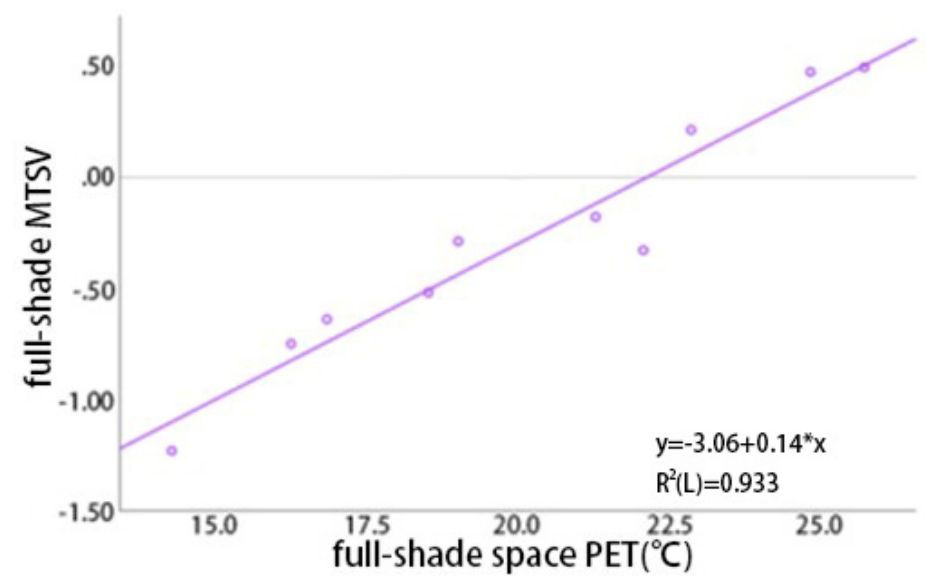

Figure 11. Full-shade PET and MTSV regression map.

\subsection{Thermal Neutral Temperature Analysis of Different Shaded Spaces in the Park}

The relationship between TSV and PET in different shading spaces was obtained by regression analysis of TSV and PET data. See Formulas (4)-(6).

$$
\begin{aligned}
& \text { No-shade space: TSV }=0.25 \times \text { PET }-5.09 \\
& \text { Half-shade space: TSV }=0.21 \times \text { PET }-4.12 \\
& \text { Full-shade space: TSV }=0.14 \times \text { PET }-3.06
\end{aligned}
$$

According to the regression equation, when TSV $=0$, visitors accept the highest temperature for the thermal neutral temperature of a full-shaded space, which is $22.2^{\circ} \mathrm{C}$; the lowest half-shaded space, which is $19.3^{\circ} \mathrm{C}$; and the thermal neutral temperature of the no-shade space, which is $20.2^{\circ} \mathrm{C}$. Visitors have different thermal comfort levels in different shaded spaces.

Furthermore, according to Formulas (4) and (5) and the thermal neutral temperature range of different shaded spaces was determined, as shown in Table 4 . The thermal neutral temperature ranges of no-shade, half-shaded, and full-shaded spaces were about 4, 5, and 7 , respectively, indicating that visitors' perceptions of temperature were similar in the no-shaded and half-shaded spaces, and are relatively consistent with the standard range. In the full-shaded space, the temperature was lower than the standard version when it was 'cool' and was above the standard range when it was 'warm', indicating that the full-shaded space requires lower and higher temperatures to perceive 'cool' and 'warm'.

Table 4. Thermal sense scale corresponding to temperature and threshold range.

\begin{tabular}{cccccccccc}
\hline & \multirow{2}{*}{ Thermal Sense Scale } & \multirow{2}{*}{$\begin{array}{c}\text { Standard } \\
\text { Range/ }{ }^{\circ} \mathbf{C}\end{array}$} & \multicolumn{2}{c}{ No-Shade Space } & \multicolumn{2}{c}{ Half-Shade Space } & \multicolumn{2}{c}{ Full-Shade Space } \\
\cline { 5 - 9 } & & $\begin{array}{c}\text { Correspond } \\
\text { Temperature }\end{array}$ & Range & $\begin{array}{c}\text { Correspond } \\
\text { Temperature }\end{array}$ & Range & $\begin{array}{c}\text { Correspond } \\
\text { Temperature }\end{array}$ & Range \\
\hline-2 & Cool & $8 \sim 13$ & 12.3 & $10.3 \sim 14.2$ & 10 & $7.6 \sim 12.3$ & 7.7 & $4 \sim 11.3$ \\
-1 & Slightly & $13 \sim 18$ & 16.2 & $14.2 \sim 18.2$ & 14.7 & $12.3 \sim 17$ & 14.9 & $11.3 \sim 18.5$ \\
0 & cooler & Moderate & $18 \sim 23$ & 20.2 & $18.2 \sim 22.2$ & 19.3 & $17 \sim 21.7$ & 22.2 & $18.5 \sim 25.8$ \\
1 & Slightly & $23 \sim 29$ & 24.2 & $22.2 \sim 26.1$ & 24 & $21.7 \sim 26.4$ & 29.4 & $25.8 \sim 33$ \\
2 & warmer & Warm & $29 \sim 35$ & 28.1 & $26.1 \sim 30.1$ & 28.7 & $26.4 \sim 31.6$ & 36.7 & $33 \sim 40.2$ \\
\hline
\end{tabular}

\subsection{Analysis of PET, MTSV and Crowd Aggregation Densit}

As shown in Table 5, the correlation between PET and crowd aggregation density was determined. PET had a significant positive correlation with the crowd aggregation density 
in the three types of shaded spaces: no-shade space $(r=0.841 ; p<0.01)$, half-shade space $(r=0.818 ; p<0.01)$ and full-shade space $(r=0.831 ; p<0.01)$. The PET correlation of the no-shade space was the highest, followed by that of full-shaded space, and the half-shaded spaces had the lowest correlation between the two.

Table 5. Analysis of the correlation between PET, MTSV and population aggregation density.

\begin{tabular}{ccccccc}
\hline & \multicolumn{3}{c}{ PET } & & \multicolumn{2}{c}{ MTSV } \\
\cline { 2 - 7 } & $\begin{array}{c}\text { No-Shade } \\
\text { Space }\end{array}$ & $\begin{array}{c}\text { Half-Shade } \\
\text { Space }\end{array}$ & $\begin{array}{c}\text { Full-Shade } \\
\text { Space }\end{array}$ & $\begin{array}{c}\text { No-Shade } \\
\text { Space }\end{array}$ & $\begin{array}{c}\text { Half-Shade } \\
\text { Space }\end{array}$ & $\begin{array}{c}\text { Full-Shade } \\
\text { Space }\end{array}$ \\
\hline Density & $r_{1} 0.841$ & $r_{2} 0.818$ & $r_{3} 0.831$ & $r_{1} 0.618$ & $r_{2} 0.748$ & $r_{3} 0.846$ \\
$p$ value & $p_{1}<0.01$ & $p_{2}<0.01$ & $p_{3}<0.01$ & $p_{1}<0.05$ & $p_{2}<0.01$ & $p_{3}<0.01$ \\
\hline
\end{tabular}

As shown in Table 5, the correlation between MTSV and crowd aggregation density was also determined. The three types of shaded spaces MTSV were positively correlated with crowd aggregation density, according to the findings. Correlation increased with shade area in the no-shade space $(r=0.618 ; p<0.05)$, half-shade space $(r=0.748 ; p<0.01)$ and full-shade space $(r=0.846 ; p<0.01)$. The correlation coefficient between MTSV and crowd aggregation density increased gradually, with the most significant correlation occurring in the fully-shaded space.

The correlation between the PET and population agglomeration index in the three different shading spaces was higher than the correlation between the MTSV and crowd agglomeration index, indicating that under normal circumstances, PET can better explain the change of crowd aggregation density than MTSV. However, MTSV has a certain explanatory power when the shading area is large. This is consistent with the evaluation of the heat perception characteristics of tourists in the survey results. In the no-shade space, visitors voted from 'cool' to 'hot', while those in the half-shaded spaces voted in addition to 'hot', and those in the full-shaded space voted for a relatively stable concentration.

\section{Discussion}

Research on the crowd agglomeration in different shading spaces are concentrated. Some scholars have researched thermal comfort in different shaded environments using questionnaire surveys and on-site measurements [39]. The results reflect the differences in thermal comfort of different shading [40]. However, the relationship between crowd gathering and different shading spaces is often disregarded. Therefore, the relationship between the aggregation of people flow and thermal comfort index in different shading spaces was established. It reflects the tourists' behaviour preferences with regards to thermal comfort.

The relationship between PET and TSV in different shading spaces are widely analized in thermal comfort [41]. Li YuMeng et al. [42]. employed the small-scale public space of cold cities in conducting regression analysis of PET and MTSV values in comfort and edge stages to establish the relationship between them. They found that visitors in the marginal stage were more sensitive to the thermal environment than those in the comfortable stage. Fang Xiaoshan et al. [43]. established the linear relationship between PET and MTSV, and analysed the value range of the thermal neutrality of outdoor thermal comfort for the elderly in summer. Xie Mingzhe established the linear relationship between PET and TSV [44], and the comparison of thermal comfort of outdoor squares in different seasons. However, these studies do not further analyse the relationship between PET and MTSV in different shading spaces. This research is based on different shading spaces. The sample plots are classified as no-shade space, half-shaded space, and full-shaded space. A regression model was established to analyse the relationship between PET and MTSV in the no-shade, half-shaded, and full-shaded spaces in the park. This study aims to provide a reference for improving the thermal comfort of visitors in different shaded spaces. 
A total of 140 sets of data were used in this study, all of which were within one week. Therefore, the research results cannot be extended to the whole month, quarter, or even the whole year. However, some valuable information can be noted. For example, there exists obvious correlation between thermal comfort and pedestrian flow distribution in different shading spaces. Besides, people have different sensitivity to the thermal environment under different shade spaces. The accuracy of the research could be improved if the research sample plot and the study period were expanded.

\section{Conclusions}

Based on the investigation and research conducted at Longzi Lake Beach Park, this paper employed the Baidu Heat Map, questionnaire surveys, and thermal environment observations to examine the correlation between thermal comfort and crowd aggregation density, and the relationship between various factors and thermal comfort degree. The main conclusions are as follows:

(1) There exists significant differences of thermal comfort in different shade spaces, which has a significant impact on the distribution of people.

From the analysed results, it can be seen that the thermal comfort of non-shaded space is generally 'warm' and 'slightly warm', and that the frequency of the thermal map is low. The thermal comfort of half-shaded space is mostly 'slightly warm' and 'warm', and the frequency of thermal map is higher than that of no-shaded space. The thermal comfort of the full-shade space is relatively moderate as a whole, showing the situation of 'moderate' to 'cool', and the frequency of the thermal map is high. In addition, from the analysis of the Baidu thermal map frequency of three spaces, no-shading $<$ half-shading $<$ full-shading also reflects the influence of different shading spaces on population distribution.

(2) There were also differences in the effects of PET and MTSV on population distribution under the different shading spaces.

The correlation coefficient between PET and population agglomeration density was 0.8 , indicating an obvious correlation. Furthermore, when the shading area was low or high, there were more relevant correlations. The effect of MTSV value on population aggregation density decreased with the decrease in shading area. The lowest MTSV correlation coefficient (no-shade space) was 0.618, while the highest (full-shade space) was 0.846 .

(3) People have different sensitivity to the thermal environment under different shade spaces.

Through the threshold range of the corresponding temperature in the thermal sensory scale, it is found that the spatial perception degree of the shading and half-shading is relatively uniform, and that the full-shade space can only perceive the lower and higher temperatures of 'cool' and 'warm'. In addition, the population distribution is higher than the other two types of space.

(4) The relationship between PET and MTSV in different shade spaces showed significant differences.

The correlation between PET and MTSV in different shading spaces was established in Formulas (4)-(6). The fitting coefficient of non-shaded space is 0.25 . The fitting coefficients of half-shading space and full-shading space are similar, at 0.21 and 0.14 respectively. The correlation intensity shows no-shading $>$ half-shading $>$ full-shading.

The research draws some meaningful conclusions, which are helpful to promote the construction of the park thermal environment and meet people's different outdoor activities from the perspective of shading. In the future, the accuracy of the research could be improved by expanding the research sample plot and the study period.

Author Contributions: Conceptualization, Q.F. and X.L.; methodology, Q.F.; software, X.L.; validation, Q.F., X.L. and H.L.; formal analysis, Q.F.; investigation, X.L.; resources, H.L.; data curation, X.L.; writing—original draft preparation, X.L.; writing—review and editing, H.L.; visualization, Q.F.; supervision, Q.F.; project administration, H.L.; funding acquisition, H.L. All authors have read and agreed to the published version of the manuscript. 
Funding: This study is financed by 2022 Key R\&D and Promotion Projects in Henan Province (No. 222102320064), 2022 Henan Science and Technology Think Tank Research Project (HNKJZK2022-51B), Henan ecological civilized city theory and application innovative science and technology team, 2020 Henan Science and Technology Think Tank Research Project (HNKJZK-2020-02C) and National Water Conservancy Scenic Spot Development Research Center.

Conflicts of Interest: The authors declare no conflict of interest.

\section{References}

1. Hong, X.Z.; Gui, X.T.; Xin, Y.Y.; Jing, S. Influences of greening and structures on urban thermal environments: A case study in Xuzhou City, China. Urban For. Urban Green. 2021, 66, 127386. (In Chinese) [CrossRef]

2. Lo, A.Y.; Byrne, J.A.; Jim, C.Y. How climate change perception is reshaping attitudes towards the functional benefits of urban trees and green space: Lessons from Hong Kong. Urban For. Urban Green. 2017, 23, 74-83. [CrossRef]

3. Farshid, A.; Ebrahim, S.; Sepideh, B.; Ester, H.G.; Amir, M.; Shahab, S.B. How parks provide thermal comfort perception in the metropolitan cores; a case study in Madrid Mediterranean climatic zone. Clim. Risk Manag. 2020, 30, 100245. [CrossRef]

4. Jiang, Y.; Zhao, L.H.; Meng, Q.L. Study on thermal comfort of urban pedestrian space in hot and humid areas in summer. J. Civ. Environ. Eng. 2020, 42, 174-182. (In Chinese)

5. Xi, T.Y.; Wang, Q.C.; Ding, J.H.; Qin, H. A comparative study on the differentiation of thermal comfort of tourists in cold urban scenic spots. Archit. Sci. 2019, 35, 124-129. (In Chinese)

6. Aram, F.; Solgi, E.; Holden, G. The role of green spaces in increasing social interactions in neighborhoods with periodic markets. Habitat Int. 2019, 84, 24-32. [CrossRef]

7. Xi, T.Y.; Qin, H.; Wang, H.S.; Jin, H. Study on dynamic thermal comfort of strollers in Stalin Riverside Park in summer. Archit. Sci. 2021, 37, 93-103. (In Chinese)

8. Liang, C.; Ng, E. Outdoor thermal comfort and outdoor activities: A review of research in the past decade. Cities 2012, 29, 118-125.

9. Rapoport, A. An approach to designing Third World environments. Third World Plan. Rev. 1979, 1, 23-40. [CrossRef]

10. Andrade, H.; Alcoforado, M.J.; Oliveira, S. Perception of temperature and wind by users of public outdoor spaces: Relationships with weather parameters and personal characteristics. Int. J. Biometeorol. 2011, 55, 655-680. [CrossRef] [PubMed]

11. Li, K.; Zhang, Y.F.; Zhao, L.H.; Li, X.H. Applicability of thermal comfort index in urban outdoor space in hot and humid areas. Archit. Sci. 2017, 33, 15-19, 166. (In Chinese)

12. Fang, Z.; Feng, X.; Xu, X.; Zhou, X.; Lin, Z.; Ji, Y. Investigation into outdoor thermal comfort conditions by different seasonal field surveys in China, Guangzhou. Int. J. Biometeorol. 2019, 63, 1357-1368. (In Chinese) [CrossRef]

13. Li, C.; Yang, X. A study on the vigor improvement of traditional villages in Winter based on the Simulation of ENVI-met Software-A case study of Xiaxia Village in Beijing. City Build. 2020, 17, 99-102. (In Chinese)

14. Sun, J.M. The development stage of urbanization and the relationship between urban and rural areas. Urban Rural Plan. 2018, 44-50. (In Chinese)

15. Yan, J.C.; Liang, J. Study on outdoor pedestrian thermal comfort of cold block commercial complex. Archit. Cult. 2020, 58-60. (In Chinese)

16. Zhang, J.; Li, K.; Zhao, L.H. Study on the characteristics of subjective thermal comfort evaluation of different outdoor spaces in hot and humid areas in summer. Archit. Sci. 2019, 35, 18-24. (In Chinese)

17. Feng, X.W.; He, C.X.; Fang, Z.S.; Ji, Z.L. Research status of outdoor thermal comfort. Archit. Sci. 2017, 33, 152-158. (In Chinese)

18. Zhao, S.F.; Xi, W.F.; Zhang, L. Investigation of PMV Model for Evaluation of the Outdoor Thermal Comfort. Procedia Eng. 2017, 205, 2457-2462. (In Chinese)

19. Thorsson, S.; Lindqvist, M.; Lindqvist, S. Thermal bioclimatic conditions and patterns of behaviour in an urban park in Göteborg, Sweden. Int. J. Biometeorol. 2004, 48, 149-156. [CrossRef]

20. Fanger, P.O. Thermal Comfort. Analysis and Applications in Environmental Engineering; Danish Technical Press: Copenhagen, Denmark, 1970; p. 244.

21. Gagge, A.P. A Standard Predictive Index of Human Response to the Thermal Environment. ASHRAE Trans. 1986, 92, 709-731.

22. Hoppe, P. The physiological equivalent temperature-A universal index for the biometeorological assessment of the thermal environment. Int. J. Biometeorol. 1999, 43, 71-75. [CrossRef]

23. Matzarakis, A.; Rutz, F.; Mayer, H. Modelling radiation fluxes in simple and complex environments: Basics of the RayMan model. Int. J. Biometeorol. 2010, 54, 131-139. [CrossRef] [PubMed]

24. Feng, G.H.; Liang, R.B.; Ning, J.Y.; Gao, Y.; Guo, Z. Analysis of the effect of solar radiation on human thermal comfort. J. Shenyang Constr. Univ. 2007, 790-793. (In Chinese)

25. Liu, Y.H.; Xu, Y.M.; Zhang, F.M.; Shu, W.J. Study on the influence of urban spatial morphology on the distribution of heat island in Beijing. J. Geogr. 2021, 76, 1662-1679. (In Chinese)

26. Duan, Y.X.; Jin, H.X.; Shi, X. Study on the effect of landscape architecture spatial canopy shading on summer microclimate and human thermal comfort-A case study of Hangzhou Sanatorium of Nanjing military region. Chin. Gard. 2018, 34, 64-70. (In Chinese) 
27. Min, X.; Bo, H.; Run, S.J.; Le, A.; Ting, Z. Outdoor thermal comfort of shaded spaces in an urban park in the cold region of China. Build. Environ. 2019, 155, 408-420. (In Chinese)

28. Zong, S. Study on Summer Microclimate Landscape Optimization Strategy of Outdoor Public Space in Xi'an Urban Residential Area; Xi'an University of Architectural Science and Technology: Xi'an, China, 2020. (In Chinese)

29. Liu, C.; Tang, L.N. Study on the Application of Landscape Ecology in Urban ecosystem Services-Taking the land-scape design of urban parks as an example. J. Ecol. 2020, 40, 814-8146. (In Chinese)

30. Xi, T.Y.; Lei, Y.S. Study on the difference of thermal comfort between winter and summer in urban parks in severe cold areas. Archit. Sci. 2021, 37, 52-60. (In Chinese)

31. Yin, Y.Q.; Chen, K.; Wang, Y.Z. Research on the vitality of historical blocks based on the comprehensive measurement of spatial syntax and Baidu thermal map. Chin. Foreign Arch. 2021, 101-106. (In Chinese)

32. Liu, A.Q. Research on Visiting Characteristics and Influencing Factors of Urban Parks Based on Baidu Thermal Map; Nanjing Forestry University: Nanjing, China, 2021. (In Chinese). [CrossRef]

33. Liu, W.W.; Huang, Y.Q.; Kang, Z.H.; Fan, Y.; Wu, Q.S. Study on the use of Landscape Architecture Recreation Space based on Thermal Map Big data method-A case study of Hainan Xinglong Botanical Garden. J. Hainan Univ. 2019, 37, 268-275. (In Chinese)

34. Hu, W.H.; Shen, S.S.; Yang, F.; Bao, Z.Y. Research on vitality evaluation and influencing factors of historical and cultural blocks based on multi-source big data. Chin. Foreign Arch. 2021, 96-101. (In Chinese)

35. Zhou, Y.F.; Yang, J.; Zhou, J.; Zhou, P.; Liu, H. Study on vigor Measurement of Rail Transit Station Service area based on Thermal Map data-A case study of Shenzhen Metro. J. Peking Univ. 2020, 56, 875-883. (In Chinese)

36. Wang, C.L. Temporal and spatial characteristics of urban population aggregation in the main urban area of Wuhan Based on Baidu thermal map. J. West. Hum. Settl. 2018, 33, 52-56. (In Chinese) [CrossRef]

37. An, Y.J. Study on crowd aggregation in urban scenic spots based on big data of thermal map-Taking the main urban area of Nanchang as an example. Inf. Comput. 2020, 32, 143-145.

38. Tan, M.L. Study on the Effects of Relative Humidity and Wind Speed on Human Thermal Sensation in Summer; Chongqing University: Chongqing, China, 2012. (In Chinese)

39. Jiang, Y.; Xu, F.; Xiong, Y.; Liu, Z.X.; Zhao, L.H. Study on thermal comfort characteristics of slow lanes in hot and humid areas based on shading rate. Chin. Gard. 2021, 37, 71-76. [CrossRef]

40. Zhang, S.Y. Study on Thermal Comfort of Shading Environment of Green Open Space in Wuhan; Huazhong Agricultural University: Wuhan, China, 2018. (In Chinese)

41. Li, K.K.; Zhang, X.X.; Jiang, W.W. Experimental study on the relationship between microclimate and human comfort in summer park-Taking Qianwangling Park as an example. Green Technol. 2020, 16-19. [CrossRef]

42. Li, Y.M. Study on Optimization Strategy of Thermal Comfort in Transition Season of Small-Scale Public Space in Cold Cities; Harbin Institute of Technology: Harbin, China, 2019. (In Chinese). [CrossRef]

43. Fang, X.S.; Hu, J. Study on outdoor thermal comfort threshold of the elderly in hot and humid areas in summer. South. Arch. 2019, 5-12. (In Chinese)

44. Xie, M.Z.; Li, J. Comparative study on thermal comfort of several outdoor squares in hot and humid areas. City Build. 2020, 17, 52-55, 67. (In Chinese) [CrossRef] 